\title{
WHO ARE THE ADVISERS?
}

D. B. GiBBs '

Advisory Officer (Extension), MAF, Wellington

\section{Abstract}

Farmers have claimed that contact with their fellow farmers is cheir most important source of information. However, farm ad', isory officers considered such sources rather inaccurate. Conditions which encourage farmers to more actively share information among themselves are discussed. The differences between two sheep farming districts in the extent of interpersonal contact by farmers with all sources of information are highlighted. Recommendations are made on the basis of the dynamics of group interaction for ways in which a farm advisory officer may stimulate greater interaction among farmers. This encourages a better information flow and a more favourable climate for innovation and adoption of new ideas. Also, farm advisory officers must acknowledge and use the fact that, in the absence of an adviser, farmers see other farmers as their most accurate and useful source of information and advice.

\section{INTRODUCTION}

INFORMATION is the key to change and innovation. An active exchange of ideas among farmers and with their various sources of information is the basis for a vital and developing agriculture.

What is the stimulus for this interaction? Who are the advisers of our grassland farming community?

Using several recent studies on the dissemination of agricultural information (Gibbs, 1970; Gibbs and Bibby, 1979; Fairgray, 1979) along with general farm advisory experience, an appraisal of this question forms the basis of the following discussion.

\section{IMPORTANCE OF INFORMATION SOURCES}

In Fairgray's (1979) study, MAF farm advisory officers (FAOs) rated themselves highly as information sources for farmers, both in the accuracy of their information and in the quantity of the information they supplied. Not unexpectedly, the FAOs expressed a high regard for the accuracy of all MAF information 
sources, but they ranked contact with themselves as the most important source for farmers.

How valid is this ranking as far as the farmer is concerned? Are FAOs in fact the farmer's adviser? What do New Zealand farmers rate as their most useful information source?

The answer depends on the kind of information that is being sought; but, in general, it appears that the FAO is not at the top of the list. In New Zealand (as overseas), other farmers are seen as the farmer's chief source of information.

Certainly, if only those farmers who have had contact with FAOs are considered, then the farmer's rating of FAOs as information sources are encouragingly similar to the FAOs' own ratings of their importance. However, with each FAO trying to serve the needs of about 500 farmers in his district, the total extent of personal contact is likely to cover only $30 \%$ of all farmers in the district. Therefore, although the adviser is seen to be a highly useful information source to the farmers he contacts, to the majority of farmers the information obtained, in both amount and accuracy, is not as important as that they obtain from one another.

Farmers rate contact wih their fellows as the source from which they gain the most information — information that is rated for accuracy second only to MAF booklets.

Unfortunately, FAOs have not credited between-farmer cortacts with this high degree of accuracy, but ranked such contacts tenth out of twelve named information sources. They did, however, rate highly the amount of informatioa that farmers obtained from other farmers.

Between-farmer contacts obviously provide opportunities for distortion or alteration of the "truth" of information - as an FAO would see it. The study by Fairgray did not indicate any inaccuracy of the information that was obtained from other farmers, but it did indicate a change in emphasis. There appears to be a greater amount of unfavourable information accepted about MAF-promoted innovations. However, this is understandable in terms of the focus of an FAO's activities in his district. It is not possible for the FAO to allocate his time uniformly over his whole district when working on a demand basis. There will be various focal points, where farmer contact with the FAO through farm visits, discussion groups, and field days, will be more intense than in other areas. Consequently there will be a distance-dilution effect in the farmer-to-farmer spread of information from these focal points of activity. Also, information and interpretation will be- 


\section{Reporoa Survey Area}

\section{Pattern of Family Visiting.}

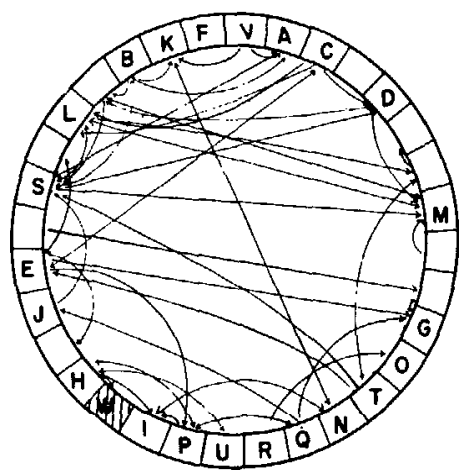

Reporoa Survey Area
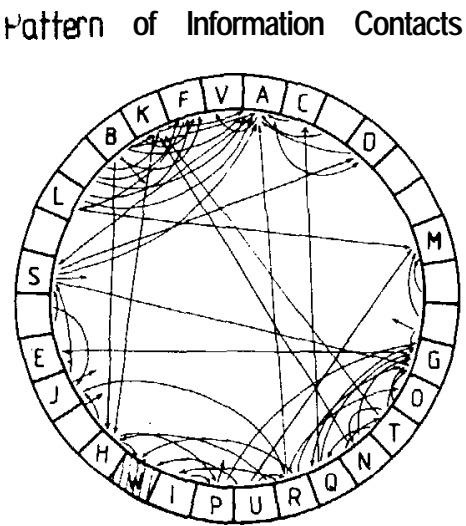

Halcombe Survey Area

Pattern of Family Visiting

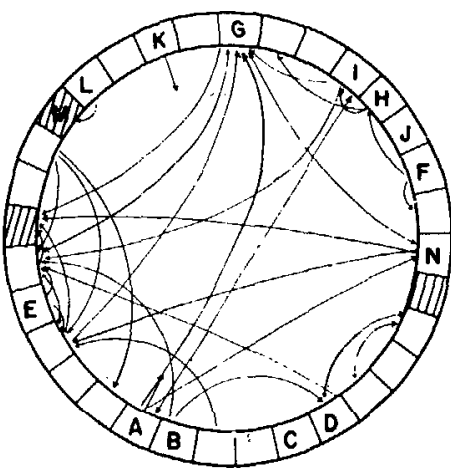

Halcombe Survey Arm

\section{Pattern of Information Contacts}

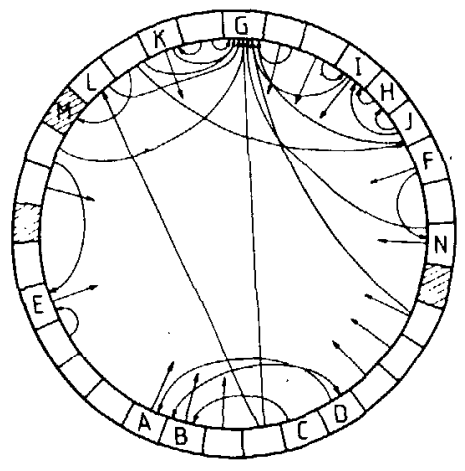

FIG. 1: Interpersonal contact diagrams of family visiting and information contacts.

Each segment in the circles represents an individual farmer in the district surveyed.

The positions around the circle were determined chiefly from the roading patterns within each area. Near neighbours are in close juxtaposition while those the greatest distance apart in each district are in general farthest apart in the diagrams too.

Letters in the segments identify individuals named by others as information sources in each district and the arrows indicate the direction interpersonal contact would, or does take place. Short arrows indicate farmers who said they talked with neighbours in general.

Shaded segments are individuals within the survey area who were not interviewed. 
come largely hearsay - there will be fewer farmers (or, perhaps, none) in the immediate vicinity who are practising a promoted innovation with whom detailed discussion or observation may be possible.

\section{BETWEEN-FARMER INTERACTION}

In the absence of an FAO, farmer-to-farmer communication is necessary, but who are the farmers who take part in this exchange of information? A previous study (Gibbs, 1970) has shown that farmers will seek information from other farmers, outside their usual social contacts, and, to some extent, even across social boundaries.

A comparison of interpersonal contact diagrams (Fig. 1) that indicated the patterns of social visiting and predicted sources of technical farm advice supports this comment.

Taking these diagrams from the two separate areas - there appears to be much more interaction in the Reporoa area than in Halcombe. This is a true difference. For example, in Reporoa, of 31 interviewees, 26 had referred to 23 other individuals as information sources; while in Halcombe, of 29 interviewees, 20 had referred to only 14 other individuals. This difference in the degree of interaction within the area was also found in the overall level of contact with the various sources of information. The Reporoa farmers made greater use of all sources of information than did the Halcombe farmers.

These two sheep farming districts had very similar physical, farm, and people characteristics, but they had vastly different histories of settlement. Reporoa was a Lands and Survey Settlement Block, with the farmers taking over their farms between 1957 and 1963. The Halcombe farmers had acquired their properties at various times since 1929 , in an area which had originally been settled in the late 1880s. The Reporoa farmers, obtaining their farms under the government soldier or civilian settlement schemes, came to a new farming district in very similar circumstances. This could not be said of the farmers who moved into the long-established Halcombe district.

The effect of these differences in settlement meant that the Reporoa farmers were thrown together in a new environment, where they recognized their problems as being common to all. Because of this, they were forced to act together, in developing farming techniques or traditions for the area. 
By contrast, Halcombe had an established tradition of farming practices. The technical problems faced by farmers in the area are likely to be seen as peculiar to the individual. Solutions must be sought within the individual's experience of the farming tradition of the district. The low level of interaction within the district means that information from any source was not as actively sought as it was in Reporoa.

\section{DYNAMICS OF INTERACTION}

It is a frequently experienced sociological feature that when people are forced to come together and to interact (as happened with Reporoa's mode of settlement), feelings of friendliness tend to develop among the people within the group. As these feelings increase, both the amount of interaction within the group and the amount of group activity rise. These activities and interactions in their turn increase the friendliness, and so on.

Group formation and activity, however, are motivated by some form of stimulus or by some environmentally imposed activity for example, an FAO's encouragement to form a discussion group, the loss of the district medical service, or a large flood. Once the need for this activity (it was information seeking and the sharing of resources in the Reporoa area) has been overcome, the need for the group interaction declines and so the group dissolves.

Increasing levels of friendship and group activity do not therefore keep on building up, ad infinitum. In fact, the critical level of activity required to get a group started is greater than the level required to prevent a group dissolving. An FAO's activities in challenging the existing attitudes and practices in an area and in supplying information to support his challenge may provide the external impetus to start the interaction cycle among a group of farmers.

With interaction, the information seeking becomes more active; the levels of knowledge attained are higher; the dissatisfaction with some productive or managerial aspects of the farm operation is likely to become greater; and the climate for change, innovation, and adoption grows more favourable. This stimulus and this type of leadership are the kinds of activity that MAF expects of its FAOs. They are to be advisers and active sources of information to their farmers.

In the absence of an adviser, other farmers become the first choice for advice. FAOs must give greater credit to this source of 
information, to this large army of unpaid "advisers". The FAO should foster and encourage interaction among his farmers, especially in areas where he is able to have only limited contact with them.

\section{ASSISTING THE FLOW}

What can these two groups (formal and informal advisers) do to help the flow of information?

Firstly, farmers: Keep an open mind and actively seek the latest information. Play an active role in your FAO's extension activities - in their field days, seminars, discussion groups, and so on. Try to promote among your fellow farmers a climate which encourages change and innovation, and which allows individuals to share their new ideas and to gain support for worthy innovations. This involves being a good listener - not being defensive when 'your ideas are being discussed, and being always constructive in your criticism. Too often, we criticize the personality behind an idea rather than the idea itself. Instead of. "You bloody idiot. What did you do that for?", isn't "I wouldn't have done it like that, I think I would have . . ." much more constructive and positive.

Secondly, FAOs: As professional advisers you should not need reminding of the points we have just discussed. You must provide the external stimulus to generate the interaction and the information seeking that are needed if farmers are to meet the challenge of the 1980s.

This stimulus can be provided through activities such as field days and discussion groups, and through the mass media. The aim must be to create an awareness that the problems or potentials are common to a district, and not just to certain individuals. Sound innovative practices hidden at the back of a farm should be "made visible" by means of a field day, or by a newspaper or journal article. Make full use of your district's success stories; a recent survey of Waikato farmers showed that this is what they like to read (Gibbs and Bibby, 1979). Identify, where you can, farmer points of information and reference and try to add to and reinforce them. Though you are the adviser for farmers with whom you have contact, FAOs must recognize (and, indeed, endeavour to exploit) the fact that the majority of farmers see other farmers as their most accurate and useful source of information and advice. 


\section{REFERENCES}

Fairgray, J. D. 'M., 1979. The Influence of Farm Advisory Officers in the Diffusion of Agricultural Innovations. Ph.D. thesis, Geography Dept, University of Auckland.

Gibbs, D. B., 1970. Communication Patterns among Sheep Farmers in Two North Island Districts of New Zealand. M.Agr.Sc. thesis, Massey University.

Gibbs, D. B.; Bibby, C. R., 1979. Farmer readership of the Waikato Times: A Survey. Exfension Res. Rep. No. 16, MAF, Wellington. 